\title{
A Study of a single phase grid connected PV inverter performance under a weak grid conditions and distorted grid voltage for Cambodia
}

\author{
Sovanna Phoeurn, Sakda Somkun \\ School of Renewable Energy and Smart Grid Technology (SGtech), Naresuan University, Phitsanulok, Thailand
}

\begin{tabular}{l}
\hline Article Info \\
\hline Article history: \\
Received Feb 13, 2020 \\
Revised Mar 19, 2021 \\
Accepted Apr 3, 2021
\end{tabular}

Keywords:

Grid synchronization

Phase-amplitude

Power regulation

PV inverter

Weak grid

\begin{abstract}
A single-phase grid-connected PV inverter performance under a weak grid is a model designed to penetrate PV energy with a weak grid. Usually, this model gets complex and unstable in power system control such as THD growth, harmonic effects, voltage surges, inverter performance. Experimental results would present the impacts on the system which would lead to instability in the grid system. This study was based on inverter performance control, a weak grid control, the grid distortion examination, and harmonic effects. To optimize this grid system, hence, the proposed methods of oscilloscope and power meter were proportionally used to control the grid impacts and stabilities. The results showed that current THD in distorted grid voltage system surged to $8.88 \%$. $\mathrm{V}_{\mathrm{PCC}}$ growth was $238.11 \mathrm{~V}$, equivalent to $8.23 \%$ in a weak grid $\left(\mathrm{X}_{\mathrm{L}}\right.$ and $\left.\mathrm{R}\right)$. Such a huge increase could prevent the grid system from transferring power for later operation. During the experiment, the inverter, S power and Q power performances stood for good operating processes without impacts on the grid performance. This method should be applied with a weak grid system because it provided information about grid stability control.
\end{abstract}

This is an open access article under the CC BY-SA license.

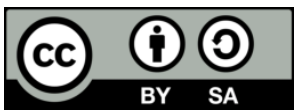

\section{Corresponding Author:}

Sovanna Phoeurn,

School of Renewable Energy and Smart Grid Technology (SGtech)

Naresuan University (NU)

Nakhon Sawan 99 Moo 9, Tha Pho Subdistrict Tha Pho, Phitsanulok, Thailand

Email: sovannaphoeurnpsd@gmail.com

\section{INTRODUCTION}

Currently, Cambodia is lacking the electric power for daily needs and industrial operations. The Royal Government of Cambodia is encouraging private development partners to invest in renewable energies, and allow people to install solar Photovoltaic systems to penetrate the low voltage grid in 2020 [1]. Cambodia is the geographically potential country for photovoltaic installations, approximately 5.8 hours per day, and average solar irradiation is $5 \mathrm{KWh} / \mathrm{m}^{2}$ [2]. Now a PV system can either operate as an off-grid system or a grid-connected system [3]. Besides, solar PV could convert direct heats of sunlight into electric energy with less maintenance. While renewable energy sources are being utilized, efficient converters and storage banks are required to prevent excessive energy consumption. These could also help to preserve energy for later use, for example, at night or during winter and rainy season when solar insulations fluctuate [4]. Inverters also play a significant role in renewable energy sources for DC to AC power conversion because it is capable of synchronizing power to the grid system [5]. Low voltage weak grid distribution systems are interfaced with renewable energy distributed generation which comprise useful impacts on power control and the operation of the network [6]. 
Furthermore, solar irradiance can deviate its power ratio by numerous natural phenomena such as heavy rainfalls and fast-moving clouds in which constant controllable active power flows (S) are incapable of managing. This factor proves that low voltage distribution systems cause serious voltage variation $(\Delta \mathrm{V})[7]$. The main problems of power interfaces require some supportive technologies and strategies to maintain grid balance on sub-synchronous resonance and harmonics which caused more difficulties in controlling such issues at device volumes [8]. The impacts of power quality transparency can lead to a weak grid and power system distortion [9]. HVDC network connected AC grid in long distance power transmission could accurately cause weak power with low effective inertia, low short circuit ratios, and operating distortions of the system [10]. As previously stated, weak grid characteristics exhibit a low short circuit current expands the sensitivity of voltage as a fault and there is an upper risk of voltage unsteadiness. While a grid system is getting weaker and weaker, naturally, there are many resolutions to reduce the various impacts of low system strength to concentrate power system control, reactive power (Q) and power transmission strengthening [11][14].

This study introduces the objectives of weak grid control and a distorted grid voltage for a singlephase grid penetrated PV inverter. The single-phase grid interfaced with impedance units in series connections with voltage $220 \mathrm{~V}$ and a system frequency $50 \mathrm{~Hz}$ where penetrated power with full-bridge PV inverter (PWM) type at PCC point. As previously stated, this research study was chosen as a single-phase full-bridge inverter for the experimental application, and today the PV inverter types branded as three significant categories in marked needs including the voltage (VSI), current (CSI), and impedance source inverters (ZSI). VSI types are the most extensively used because they naturally behave as voltage sources required by many industrial applications [15].

\section{THEORETICAL AND TECHNICAL BACKGROUND}

\subsection{Inverter power penetrated to a weak grid}

Naturally, appropriate methods of inverter power are synchronized with a single-phase weak grid depending on power quality (PQ) controller and an accurate current injection. Afterward, a synchronous reference frame is operated as an opened-loop or a closed-loop controller while the synchronous reference frame is adapted with a current controller therefrom the injected current could be synchronized with a grid voltage. In addition, as depicted in Figure 1, the phase lock loop (PLL) is reflected in grid voltage level (V) and phase angle amplitude $(\theta)$ and frequency (f) in a single-phase system [16], [17].

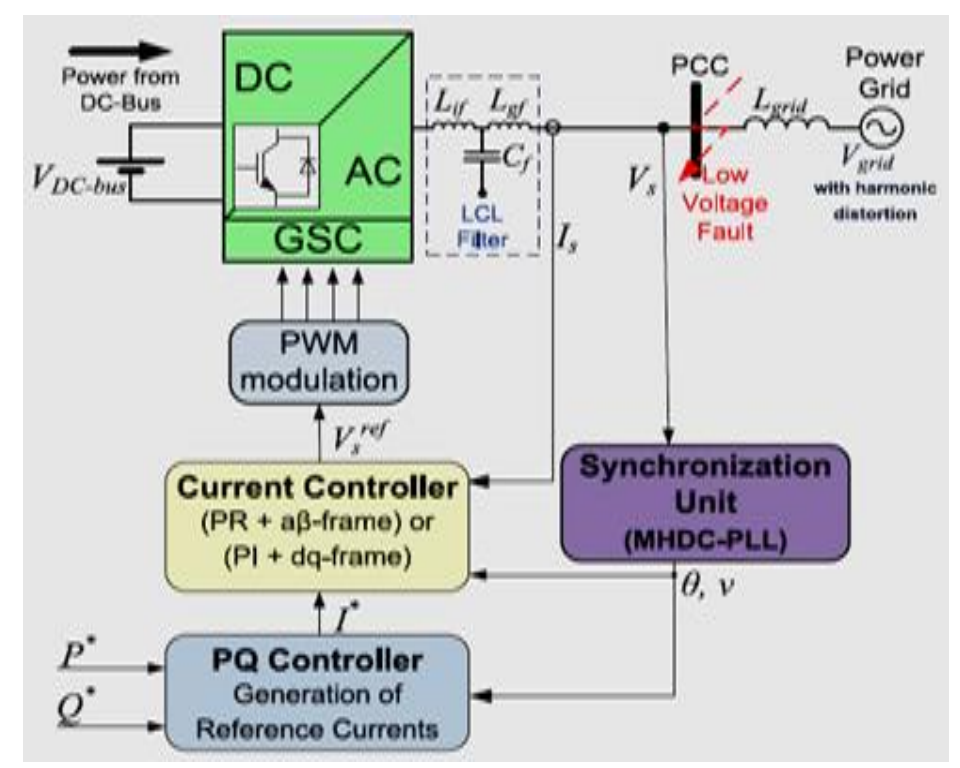

Figure 1. Power control structure synchronized a single-phase grid-tied inverter [14]

\subsection{Weak grid system (WGS)}

The distribution generation network usually comprises an internal impedance $\left(Z_{n}\right)$ which can cause the fluctuation from a connection point of a DG system with an area behavior and voltage level and 
impedance value can be calculated as shown in (1) [18]. A weak grid could lead the voltage fluctuation $(\Delta \mathrm{V})$ of the PV inverter and consequently, its effect could foment the inverter instability [19]. Otherwise, renewable energy sources (solar PV or wind) are injected into power grids can lead to the voltage deviation $(\Delta \mathrm{v})$ because of an internal system impedance, power quality decrement and high-power variations. Therefore, the active power $(\mathrm{S})$ and reactive power $(\mathrm{Q})$ are prevented strongly for grid operation[20], [21].

$$
Z_{n}=\sqrt{X_{L}^{2}+R^{2}}(\Omega)
$$

\subsection{PCC voltage control under a weak grid}

In this research, PCC voltage control was an important cause for grid tied-PV inverter system because when PV power generation system was interfaced into the power grid, power forming generation can vary, that is, PCC voltage expansion may occur and PCC voltage may be regulated for an operating system. Moreover, the maximum power output $\left(\mathrm{P}_{\max }\right)$, the active power $(\mathrm{S})$ and reactive power values $(\mathrm{Q})$ of $\mathrm{PV}$ inverters were controlled and calculated appropriately and A nonlinear of the requiring reactive power focused on against the fluctuations of the active power output with a different value of voltage variation margin. The PCC communication of a weak grid-tied PV inverter as depicted in Figure 2 and the specification of the voltage fluctuation value $(\Delta \mathrm{V})$ is utilized as the common formula[18], [22].

$$
\Delta V_{P C C}=V_{P C C}-V_{R e f}
$$

Hence,

$\Delta \mathrm{V}_{\mathrm{PCC}}$, voltage variation at point of connection coupling $(\mathrm{V})$

$\mathrm{V}_{\mathrm{PCC}}$, voltage value between the grid and PV inverter output voltage (V)

$\mathrm{V}_{\text {Ref }}$, regulated voltage source/fundamental voltage $(220 \mathrm{~V})$

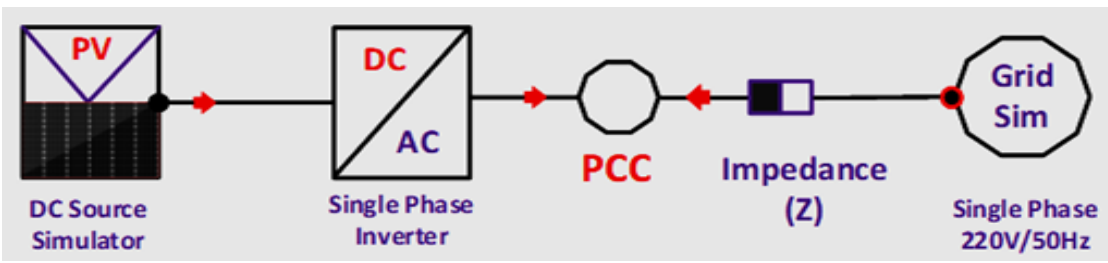

Figure 2. PCC communication of a weak grid-tied PV inverter

There are two core indicators reflect the foundation of the grid strength at PCC, that is, the short circuit ratio (SCR) or the inductive-resistive ratio (IRR) of the weak grid system defined by the mathematical equation and when the grid is considered weak if IRR is smaller than 0.5 [18].

$$
S C R=\frac{V_{P C C n o m}^{2}}{Z_{\text {total }} S_{\text {no min al }}} \text { or IRR }=\frac{X_{\text {total }}}{R_{\text {total }}}
$$

Hence,

$\mathrm{S}_{\text {nominal }}$ is the rated apparent power of the DG unit

$\mathrm{Z}$ total is the equivalent impedance

$\mathrm{V}_{\text {PCC nom }}$ is the generated rated voltage for the DG connection point

The weak/low grid was marked when the voltage at PCC point is sensitive to any deviation of load and impedance of the line is inversely proportional to the short circuit current capability at the connecting point. If the short circuit current is high, grid strength is high. While short circuit current is low strength, is a weak line. If strong/stiff grid is notified that the voltage will not be affected and will stay unchanged because depending on the impedance values of the grids. If impedance ratios are high, the strength is weak and when impedance values decrease lowly, the grid capacity strength is strong and the comparison of the weak grid and strong grid characteristics as depicted in Table 1 [23]. 
Table 1. Comparison of the weak grid and strong grid characteristics [23]

\begin{tabular}{|c|c|}
\hline Weak /Low grid capacity & Strong/stiff grid capacity \\
\hline $\begin{array}{l}\text { - Decreasing the grid SCR } \\
\text { - The growth of high grid impedance } \\
\text { - Characteristic of an unstable distributed } \\
\text { system } \\
\text { - Farther power generation location } \\
\text { - Load variation of line } \\
\text { - A voltage variation is not proportional to a } \\
\text { condition }\end{array}$ & $\begin{array}{l}\text { - Voltage still keeps steady of line } \\
\text { - Grid impedance is low } \\
\text { - The impedance of the line is inversely } \\
\text { proportional to the SCR capacity at the point of } \\
\text { common coupling } \\
\text { - The constant load of line and stable distributed } \\
\text { system } \\
\text { - Not the farther power generation location }\end{array}$ \\
\hline
\end{tabular}

\subsection{Distorted grid voltage system}

The power distribution generation systems of grid-tied PV inverters naturally comprise the grid power distortion in many causes; THD value expansion of high impedance and inverter filters in use of power electronic devices or otherwise, a low voltage distribution grid is exposed to voltage inequity, distortions and power dips [24]. The grid distortion system can cause by a solar PV irradiance decreases due to low power operation, the inverter characteristics could phenomenally generate more undesirable harmonic. Incidentally, when harmonics are flowing through power grid impedance, they produce the voltage harmonics and shall distort the supply voltage in the grid and harmonic distortions of the grid consist of $1^{\text {st }}$, $3^{\text {rd }}, 5^{\text {th }}, 7^{\text {th }}, 9^{\text {th }}$ or $11^{\text {th }}$ order values as shown in Figure 3 [25].
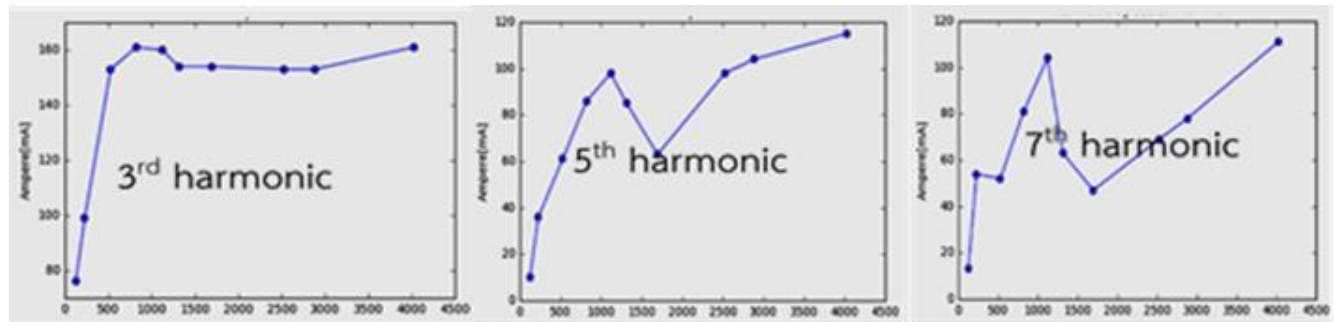

Figure 3. Current harmonic distortion with power

\subsection{Power regulation of grid code in Cambodia}

\subsubsection{Voltage category in Cambodia}

The distribution system is used to transfer electrical power to users from the high voltage (HM)/Medium voltage (MV) and the MV/Low voltage (LV) system. In addition, the voltage standard is applied in Cambodia as demonstrated in Table 2 [22].

Table 2. Voltage classification of Cambodia [26]

\begin{tabular}{llll}
\hline Voltage classification & \multicolumn{1}{c}{ Range of Nominal voltage } & Nominal voltage & Highest voltage \\
\hline Low voltage & 600v or less & $230 \mathrm{~V} / 400 \mathrm{~V}$ & - \\
Medium voltage & More than $600 \mathrm{~V}$ to $35 \mathrm{kV}$ or less & $22 \mathrm{kV}$ & $24 \mathrm{kV}$ \\
Highest voltage & More than $35 \mathrm{kV}$ & $115 \mathrm{kV}$ & $123 \mathrm{kV}$ \\
& & $230 \mathrm{kV}$ & $245 \mathrm{kV}$ \\
\hline
\end{tabular}

\subsubsection{Low voltage fluctuation}

The voltage fluctuation could appear at the grid connection point of solar PV plant because of switching operation with the solar plant facilities and the voltage fluctuations at the grid connection point of the low voltage distribution network which is penetrated with solar PV power plant become the most universal due to the intermittent nature of solar PV source and due to the customer. The load voltage fluctuation is passed by the Electricity Authority of Cambodia, $-10 \%$, and $+6 \%$ of the normal voltage value as shown in Table 3 [27]. The power factor (PF) of grid code in Cambodia is passed by Electricity Authority of Cambodia (EAC) for grid system requires 0.95 leading or lagging [28], and the system frequency is above $50.5 \mathrm{~Hz}$ or below $47.5 \mathrm{~Hz}$. The solar PV project can be disconnected from the grid supply within 0.2 seconds 
which is regulated by EAC, but the system frequency magnitudes between 47.5 to $50.5 \mathrm{~Hz}$ shall be maintained for the grid system operation.

Table 3. Low voltage levels maintained at the grid point

\begin{tabular}{cc}
\hline Nominal system voltage & Maintained Value \\
\hline $230 \mathrm{~V}$ & $207 \mathrm{~V} \leq \mathrm{U} \leq 244 \mathrm{~V}$ \\
$00 \mathrm{~V}$ & $360 \mathrm{~V} \leq \mathrm{U} \leq 424 \mathrm{~V}$ \\
\hline
\end{tabular}

\subsubsection{Harmonic distortion}

The harmonic voltage distortion is usually defined as the grid system that shall cause the harmonics in the CTS to exceed the limits specified by EAC and the overall total rated current distortion (TRD) is limited 5\% and the harmonic voltage distortion levels as illustrated in Table 4 [28].

Table 4. Harmonic voltage distortion levels

\begin{tabular}{ccc}
\hline $\begin{array}{c}\text { Bus Voltage at Point of } \\
\text { Coupling }\end{array}$ & $\begin{array}{c}\text { Max individual Harmonic } \\
\text { Component }(\%)\end{array}$ & Max THD (\%) levels \\
\hline $69 \mathrm{kV}$ and less & $3.0 \%$ & $5.0 \%$ \\
$69 \mathrm{kV}<\mathrm{V} \geq 161 \mathrm{kV}$ & $1.5 \%$ & $2.5 \%$ \\
Above $161 \mathrm{kV}$ & $1 \%$ & $1.5 \%$ \\
\hline
\end{tabular}

\section{RESEARCH METHOD}

In this research, a PV inverter penetrated power to a weak grid at the point connection of coupling (PCC) and the experiment was developed according to a simulated method to notify the research findings of the PV inverter performance, the distorted grid voltage and harmonic effects under a weak grid condition of the system. The 5-KW full-bridge inverter was set up for an experiment and the grid system was a singlephase AC power $(220 \mathrm{~V} / 50 \mathrm{~Hz})$ combined in series connection with impedance components $(\mathrm{Z})$. The impedance elements were given their total ratios of $2.619 \Omega$. Moreover, the experiment were done with total power adjustment of 5-KW PV inverter in 100\%, 66\%, 33\% range application. The experimental geographic area was set at Cambodian-Thai Skills Development Institute (CTSDI), Phnom Penh Cambodia. Particularly, the principles of experimental processes in the research study could be applied properly in the following stages such as the ideal grid system, a distorted grid voltage system, and a weak grid system. In addition, the research methodoloy titled a study of a single phase grid connected PV inverter performance under a weak grid conditions and distorted grid voltage wil be apoplied as illustrated in Figure 4.

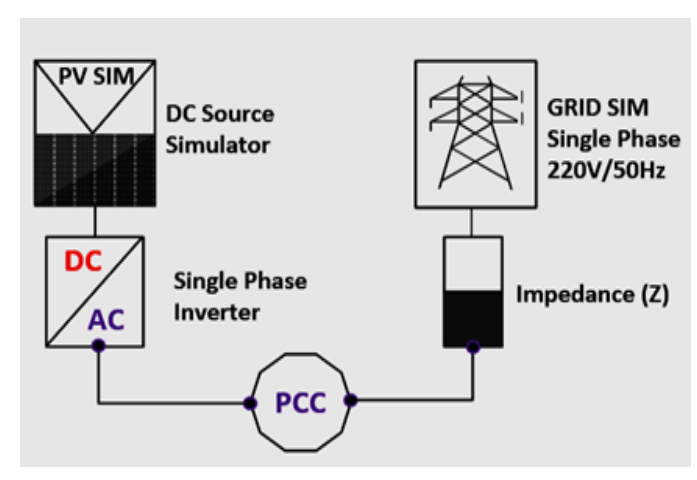

Figure 4. The research flow chart of the methodology

\section{RESULTS AND ANALYSIS}

In this segment, the results of the research study are exhibited and discussed particularly. As previously stated in the research method, there are three different experiments to detect the factors which affect the system process and the weak grid system. A PV inverter performance is delayed about 60 seconds before grid power injection.

\subsection{Results under the ideal grid system}


As depicted in the research methodology, the three-different experiments are operated properly. They are the idea grid, a distorted grid voltage and a weak grid system with $100 \%, 66 \%$ and $33 \%$ power adjustment. This is the experimental diagram of the ideal grid system as illustrated in Figure 5.

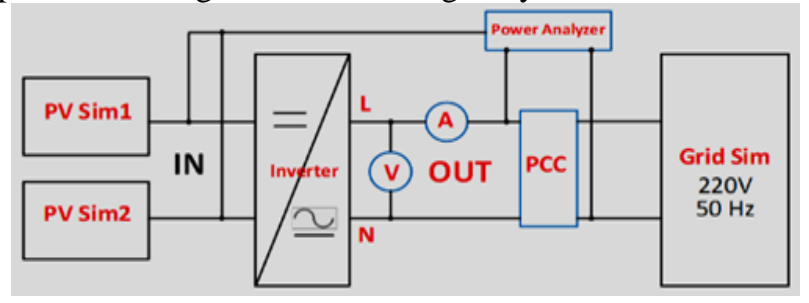

Figure 5. The experiment of an ideal grid and distorted grid system

Table 5 demonstrates the power quantities of PV simulations in 100\%, 66\%, and 33\% power applications which are being penetrated power with the grid power system.

Table 5. Power adjustment of PV simulation

\begin{tabular}{ccc}
\hline $100 \%$ power & $66 \%$ power & $33 \%$ power \\
\hline $5228.4 \mathrm{~W}$ & $3443.3 \mathrm{~W}$ & $1705 \mathrm{~W}$ \\
\hline
\end{tabular}

The experimental results of the ideal grid system are illustrated in Table 6 without the impedance component passing, is that, $\mathrm{PV}$ power system is penetrated simply with the grid system.

Table 6. Results of the ideal grid system

\begin{tabular}{ccccccccc}
\hline Description & $\begin{array}{c}\text { Power } \\
(\mathrm{W})\end{array}$ & $\begin{array}{c}\text { Voltage } \\
(\mathrm{V})\end{array}$ & $\begin{array}{c}\text { Current } \\
(\mathrm{A})\end{array}$ & $\begin{array}{c}\mathrm{P}_{\text {act }} \\
(\text { KVA })\end{array}$ & $\begin{array}{c}\mathrm{P}_{\text {reac }} \\
(\text { Kvar })\end{array}$ & $\begin{array}{c}\text { Frequency } \\
(\mathrm{Hz})\end{array}$ & $\begin{array}{c}\text { THDi } \\
(\%)\end{array}$ & Power factor \\
\hline $100 \%$ & 5070.9 & 220.31 & 23.02 & 5.0712 & 0.05 & 50 & 2.14 & 0.99 \\
$66 \%$ & 3313.2 & 220.30 & 15.04 & 3.3147 & 0.09 & 50 & 2.19 & 0.99 \\
$33 \%$ & 1652.3 & 220.16 & 7.51 & 1.6541 & 0.07 & 49.99 & 3.41 & 0.99 \\
\hline
\end{tabular}

The experimental results under the ideal grid system show that a PV simulation connected to an inverter injected power with a single-phase grid at PCC point. While the experiments were being applied, $\mathrm{P}_{\text {out }}$ values of 3-level power remarkably rose in the grid and these surges factors were caused by load power consumed, inverter output power and system power in ordinary status. During that period, $\mathrm{V}_{\text {PCC }}$ values observed the $\mathrm{V}_{\mathrm{PCC}}$ magnitudes increase a little bit of a basic voltage. Accurately, $\mathrm{V}_{\mathrm{PCC}}$ value increased due to low consumed load $(\mathrm{R})$, and frequency systems were considered as constant $50 \mathrm{~Hz}$. While voltage surge occurred in the grid to lead $\mathrm{I}_{\mathrm{PCC}}$ in a good rise.

The active power $(\mathrm{S})$ and reactive power $(\mathrm{Q})$ of the ideal grid reach good levels; therefore, $\mathrm{P}_{\text {out }}$ quantities reflect an inverter performance and the inverter efficiencies are good, equivalent to $96 \%$ which calculated as shown in (4). Although, these grid systems have an excellent process and considered as stabilized systems, current THD values $(2.14,2.19$, and $3.41 \%)$ were observed these values situated in high levels, and factors were assumed from the cause of internal grid impedance and inverter $\mathrm{P}_{\text {out }}$. Furthermore, THD effects can lead to the unsmooth current flow pathway and the ripple current waveform of the grid system.

$$
\eta_{\text {inv }}=\frac{P_{\text {out }}}{P_{\text {in }}}=\frac{I_{a c} V_{a c} \operatorname{Cos} \theta}{I_{d c} V_{d c}} \eta_{\text {inv }}=\frac{5070.9}{5228.4}=96 \%
$$

The experimental results in Table 7 demonstrated the current harmonic order values of the ideal grid system which the whole network system is allowed to naturally operate.

Table 7. The harmonic order value under the ideal grid system

\begin{tabular}{lcccccc}
\hline Harmonic orders & $1^{\text {st }}$ & $3^{\text {rd }}$ & $5^{\text {th }}$ & $7^{\text {th }}$ & $9^{\text {th }}$ & THD \\
\hline Current $100 \%$ & 22.64 & 0.30 & 0.18 & 0.08 & 0.07 & 2.14 \\
\hline
\end{tabular}




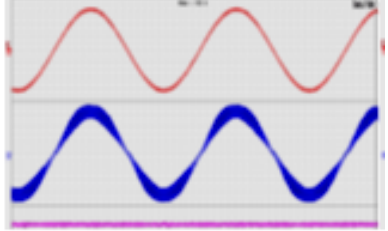

(a)

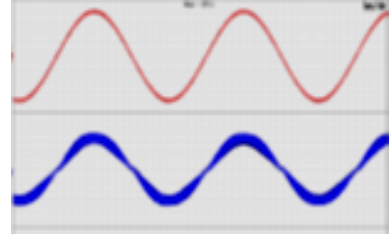

(b)

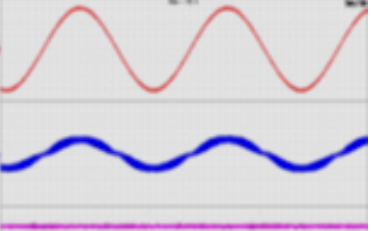

(c)

Figure 6. Grid current waveforms under ideal grid system (a) PCC current waveforms 100\% in power, (b). PCC current Waveforms in $66 \%$ power, (c) PCC ccurrent waveforms $33 \%$ in power

\subsection{Results under the distorted grid voltage system}

The distorted grid voltage system was separated into two portions for the experimental processes; the percent rate insertions on harmonic orders. The percent rate verified that $5 \%$ rate for $3^{\text {rd }}$ harmonic, $1 \%$ rate for $5^{\text {th }}, 7^{\text {th }}$ and $9^{\text {th }}$ harmonics as shown in Table 8 on harmonic spectrums and the only $3^{\text {rd }}$ harmonic order value selection. However, these experimental results were not referred extremely to voltage harmonic detections. Otherwise, current THD values were calculated as in equation (5) because harmonic effects could affect the grid application.

$$
\operatorname{THDi}(\%)=\frac{\sqrt{I_{2}^{2}+I_{3}^{2}+I_{4}^{2}+\ldots I_{n}^{2}}}{I_{1}} \times 100
$$

\subsubsection{The results of the percent rate insertions on harmonic orders}

Table 8 demonstrates the experimental results of the percentage rate insertions by emphasizing THDi magnitudes with power range adjustment in $100 \%, 66 \%$ and $33 \%$ power.

Table 8 . The results of the percent rate insertion on harmonic orders

\begin{tabular}{ccccccccc}
\hline Description & $\begin{array}{c}\text { Power } \\
(\mathrm{W})\end{array}$ & $\begin{array}{c}\mathrm{V}_{\text {PCC }} \\
(\mathrm{V})\end{array}$ & $\begin{array}{c}\mathrm{I}_{\mathrm{PCC}} \\
(\mathrm{A})\end{array}$ & $\begin{array}{c}\mathrm{P}_{\text {act }} \\
(\text { KVA })\end{array}$ & $\begin{array}{c}\mathrm{P}_{\text {reac }} \\
(\text { Kvar })\end{array}$ & $\begin{array}{c}\text { Frequency } \\
(\mathrm{Hz})\end{array}$ & $\begin{array}{c}\text { THDi } \\
(\%)\end{array}$ & Power factor \\
\hline $100 \%$ & 4978.5 & 220.26 & 22.67 & 4.9787 & 0.05 & 49.99 & 3.41 & 0.99 \\
$66 \%$ & 3318.5 & 220.27 & 15.14 & 3.3192 & 0.06 & 50 & 5 & 0.99 \\
$33 \%$ & 1646.6 & 220.26 & 7.55 & 1.6479 & 0.06 & 50 & 8.88 & 0.99 \\
\hline
\end{tabular}

The results of the percent rate insertions on harmonic orders under a distorted grid voltage system are similar to the ideal grid system, but a different figuration of a system flow is that, the grid power side passes the percent rate insertion area on harmonic orders and injected power with PV inverter power at PCC. The results show in $100 \%$ power gets $4978.5 \mathrm{~W}$ and this value collapses around $21.5 \mathrm{~W}$ of $5 \mathrm{KW}$ inverter capacity and in $33 \%$ power falls about $5 \mathrm{~W}$, but the $66 \%$ power application value rises around $19 \mathrm{~W}$. Power growth or decrement factors assumed from relations to the load power quantity consumed, system power and inverter power side. While the system power increased or collapsed, power factors could lead a current rate to follow because current ratios were proportional to power quantity levels. Otherwise, AC power system was proportional directly to the current and the voltage including an inverse proportion to power factor of the system practiced as shown in (6). In those, the harmonic distortions occur in grid systems and harmonic frequencies in power grids are the causes of power quality issues. $\mathrm{V}_{\mathrm{PCC}}$ values rise slightly of a fundamental voltage and particularly, therefore, $\mathrm{V}_{\mathrm{PCC}}$ surges cause by consumed loads and while voltage growths occur and grid powers decrease in the system, thus these factors can lead $\mathrm{I}_{\mathrm{PCC}}$ in a drop during grid frequency systems are considered as constant of frequency $50 \mathrm{~Hz}$. Referring to results, the power dropping in 100\% application leads the inverter efficiency to falls $1 \%$ of the system, equal to $95 \%$ that period the active power (S) collapses and reactive power $(\mathrm{Q})$ considered as good ranks.

$$
\text { Power }_{A C}=\text { V.I.PF }(W)
$$

Figure 7 (a) verifies each harmonic order values in the system to hold constant, but THDi values increased highly until $3.41 \%$ as shown in Table 9, if comparing with the ideal grid system. The THD expanding comes from the causes of percent addition rates on the grid harmonics including internal grid 
impedance. THD magnitude in $100 \%$ power adjustment as depicted above, it will be allowed a grid for the simple operation.

Figure 7 (b) demonstrates each harmonic order value is steady and enable for the grid system but the THDi amplitude in $66 \%$ power adjustment increases remarkably until $5 \%$ of the system, but this ratio does not surpass yet the power regulation Cambodia as shown in Table 4. THDi ratio is a scenario which illustrates the current waveform can process in unsmooth situation and this magnitude growth is possible to lead the serious distortion of the grid system, in addition, it causes extremely the ripple waveform.

Figure 7 (c) illustrates THDi value increase in the highest level $(8.88 \%)$, but each current harmonic order ratio decreases slightly of the constant levels. According to power transmission regulation of grid code Cambodia as shown in Table 4, this magnitude is a scenario of a grid system which be not permitted to operate continuously or the line system is stopped suddenly.

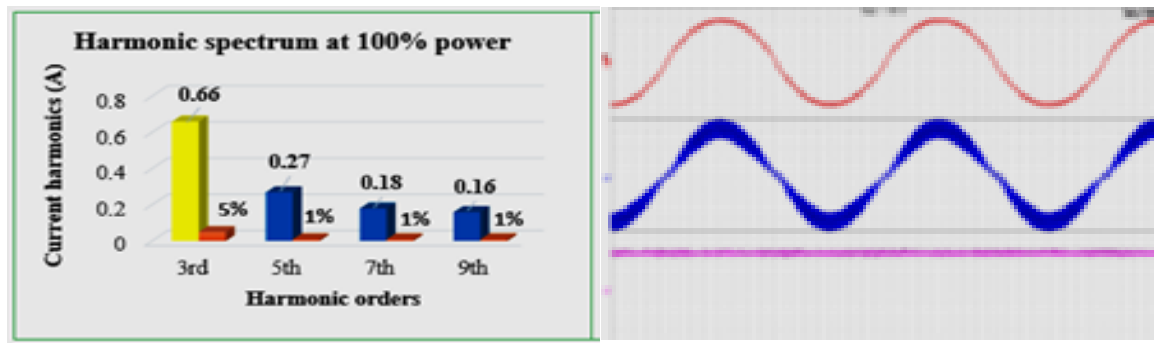

(a)

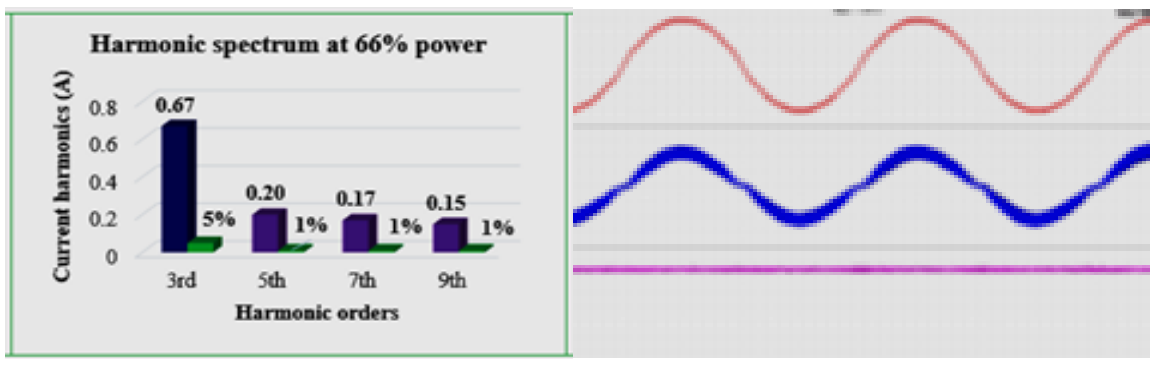

(b)

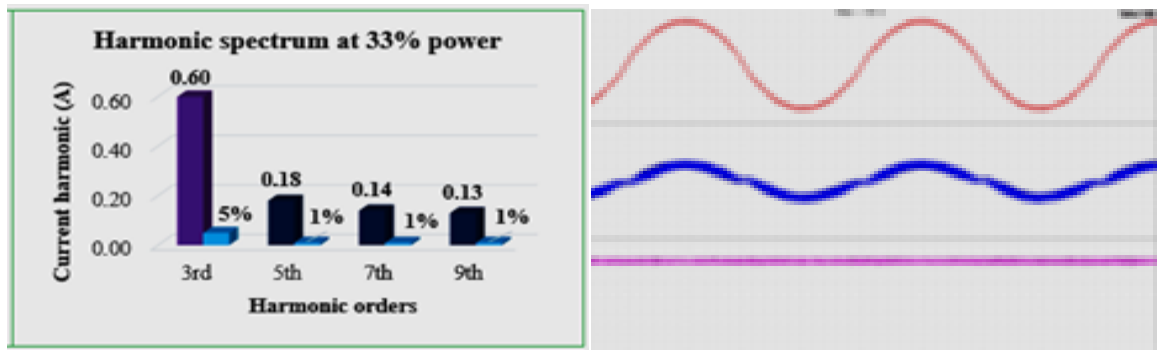

(c)

Figure 7. PCC current waveforms in percentage power, (a) $100 \%$, (b) $66 \%$, and (c) $33 \%$

Table 9. The harmonic order value under the distorted grid

\begin{tabular}{lcccccc}
\hline Harmonic orders & $1^{\text {st }}$ & $3^{\text {rd }}$ & $5^{\text {th }}$ & $7^{\text {th }}$ & $9^{\text {th }}$ & THD \\
\hline Current 100\% & $22.67 \mathrm{~A}$ & $0.66 \mathrm{~A}$ & $0.27 \mathrm{~A}$ & $0.18 \mathrm{~A}$ & $0.16 \mathrm{~A}$ & $3.41 \%$ \\
Current 66\% & $15.08 \mathrm{~A}$ & $0.67 \mathrm{~A}$ & $0.20 \mathrm{~A}$ & $0.17 \mathrm{~A}$ & $0.15 \mathrm{~A}$ & $5.00 \%$ \\
Current 33\% & $7.51 \mathrm{~A}$ & $0.60 \mathrm{~A}$ & $0.18 \mathrm{~A}$ & $0.14 \mathrm{~A}$ & $0.13 \mathrm{~A}$ & $8.88 \%$ \\
Voltage harmonics & & $5 \%$ & $2 \%$ & $1 \%$ & $1 \%$ & $5.57 \%$ \\
\hline
\end{tabular}

\subsubsection{The only 3rd harmonic order value selection}

Results of the only $3^{\text {rd }}$ harmonic order selection under distorted grid voltage in Table 10 is the same process system to the percent rate insertions on harmonic with a grid power injection passing $5 \%$ additional area for $3^{\text {rd }}$ harmonic order to penetrate PV inverter power. The results show $\mathrm{P}_{\text {out }}$ in $100 \%$ power collapses 
around $22 \mathrm{~W}$ of $5 \mathrm{KW}$ inverter capacity and in $33 \%$ power collapses around $5 \mathrm{~W}$. The decrement factors assumed from relation to the load power quantity consumed, system power, and a $\mathrm{P}_{\text {out. inv }}$ side. By the way, harmonic distortions lead a system power drop and the power dropping in 100\% application leads the inverter efficiency to falls $1 \%$ of the system, equal to $95 \%$. $\mathrm{I}_{\mathrm{PCC}}$ decrement in $100 \%$ power drops $0.34 \mathrm{~A}$ of $23 \mathrm{~A}$ pure value and a dropping reason comes from power factor and voltage rate of the system. Results verify additionally max voltage surge of the only $3^{\text {rd }}$ harmonic order selection is about $0.33 \mathrm{~V}$ of a basic voltage. The main factors of voltage surges caused by load power quantity and power quality in a system and grid frequencies considered as steady. $\mathrm{S}$ decrement rate cause of the disturbance in a power system and $\mathrm{Q}$ performances approach into good ranks.

Table 10. The results of the only $3^{\text {rd }}$ harmonic order selection

\begin{tabular}{ccccccccc}
\hline \multirow{2}{*}{ Description } & $\begin{array}{c}\text { Power } \\
(\mathrm{W})\end{array}$ & $\begin{array}{c}\mathrm{V}_{\text {PCC }} \\
(\mathrm{V})\end{array}$ & $\begin{array}{c}\mathrm{I}_{\mathrm{PCC}} \\
(\mathrm{A})\end{array}$ & $\begin{array}{c}\mathrm{P}_{\text {act }} \\
(\mathrm{KVA})\end{array}$ & $\begin{array}{c}\mathrm{P}_{\text {reac }} \\
(\text { Kvar })\end{array}$ & $\begin{array}{c}\text { Frequency } \\
(\mathrm{Hz})\end{array}$ & $\begin{array}{c}\text { THDi } \\
(\%)\end{array}$ & Power factor \\
\hline $100 \%$ & 4978.1 & 220.33 & 22.66 & 4.9786 & 0.06 & 49.99 & 3.14 & 0.99 \\
$66 \%$ & 3332.7 & 220.24 & 15.19 & 3.3329 & 0.02 & 50 & 4.67 & 0.99 \\
$33 \%$ & 1646.4 & 220.18 & 7.54 & 1.6471 & 0.04 & 49.99 & 8.26 & 0.99 \\
\hline
\end{tabular}

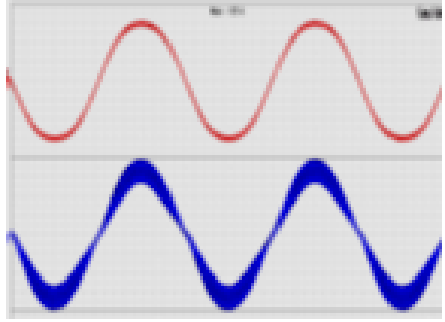

(a)

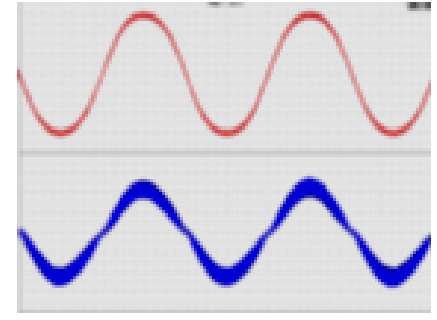

(b)

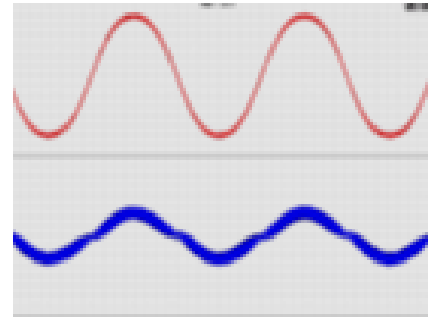

(c)

Figure 9. PCC current waveforms of the only 3rd harmonic order selection, (a) 3rd harmonic order in 100\% power, (b) 3rd harmonic order in $66 \%$ power, (c) 3rd harmonic order in $33 \%$ power

Table 11 illustrates the experimental results of the distorted grid system by emphasizing on current harmonic order magnitudes; $1^{\text {st }}$ harmonic, $3^{\text {rd }}$ harmonic, $5^{\text {th }}$ harmonic, $7^{\text {th }}$ harmonic and $9^{\text {th }}$ harmonic and before the whole system starts, the power source is adjusted in $100 \%, 66 \%$ and $33 \%$ power.

Table 11. The harmonic order value under the distorted grid

\begin{tabular}{lcccccc}
\hline Harmonic orders & $1^{\text {st }}$ & $3^{\text {rd }}$ & $5^{\text {th }}$ & $7^{\text {th }}$ & $9^{\text {th }}$ & THD \\
\hline Current 100\% & $22.65 \mathrm{~A}$ & $0.66 \mathrm{~A}$ & $0.18 \mathrm{~A}$ & $0.08 \mathrm{~A}$ & $0.07 \mathrm{~A}$ & $3.14 \%$ \\
Current 66\% & $15.15 \mathrm{~A}$ & $0.68 \mathrm{~A}$ & $0.12 \mathrm{~A}$ & $0.08 \mathrm{~A}$ & $0.06 \mathrm{~A}$ & $4.67 \%$ \\
Current 33\% & $7.51 \mathrm{~A}$ & $0.59 \mathrm{~A}$ & $0.10 \mathrm{~A}$ & $0.06 \mathrm{~A}$ & $0.05 \mathrm{~A}$ & $8.26 \%$ \\
Voltage harmonics & & $2.5 \%$ & $1 \%$ & $0.5 \%$ & $0.5 \%$ & $2.78 \%$ \\
\hline
\end{tabular}

According to $3^{\text {rd }}$ harmonic order magnitudes in the harmonic spectrum bars in Figure 10 notify these values to exist good stability in grid systems. But THDi values in $100 \%$ and $66 \%$ powers rise in high levels and THDi growths come from the causes of percent addition rates on the grid harmonics including internal grid impedance and non-linear loads. Therefore, harmonic effects lead to seriously distorted grid operations and badly ripple current waveforms. THDi value in $33 \%$ application rises to $8.26 \%$ and is an affected value under the regulated warning relying on power regulation of grid code, Cambodia, as shown in Table 4 . Furthermore, the $8.26 \%$ value is not allowed to transfer power or disconnected suddenly the operating system. 


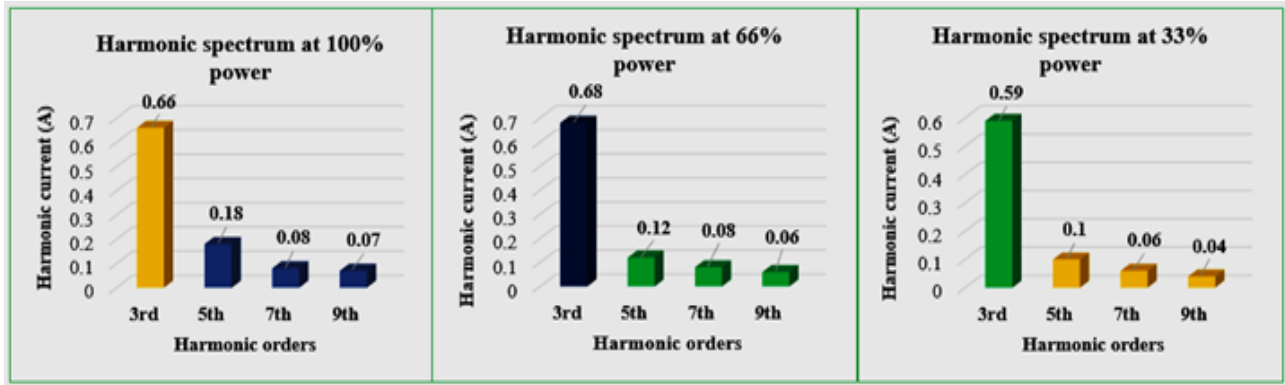

Figure 10. Harmonic spectrums of the only 3rd harmonic order selection

$$
\operatorname{THDv}(\%)=\frac{\sqrt{V_{3}^{2}+V_{5}^{2}+V_{7}^{2}+V_{9}^{2}+\ldots V_{n}^{2}}}{V_{1}} \times 100
$$

\subsection{The Results of a weak grid system}

The weak grid system is a single-phase grid-connected in series with inductive reactance $\left(\mathrm{X}_{\mathrm{L}}\right)$ and resistive (R) units and penetrated power with PV inverter at the point of common coupling (PCC). $\mathrm{X}_{\mathrm{L}}$ values are given $1.749 \Omega$ and $\mathrm{R}$-value is $0.87 \Omega$, totally summarized values are accepted $2.619 \Omega$. The weak grid system provided into individual two structures for the experiment with power adjustment as previously stated. The first experiment strategy of a weak grid is applied in power transference passing impedance $\left(\mathrm{X}_{\mathrm{L}}\right)$ from the grid- connected PV inverter, and the second is a weak grid applied in power transference throughout impedances $\left(\mathrm{X}_{\mathrm{L}}-\mathrm{R}\right)$ from a grid penetrated a $\mathrm{PV}$ inverter power.

\subsubsection{The results of a weak grid system connected inductive reactance (XL)}

A weak grid system connected an inductive reactance in series to a grid simulator with $1.749 \Omega$ known value and synchronized with PV power system at PCC point to analyse judiciously the power network and simulated the technical diagram as shown in Figure 11.

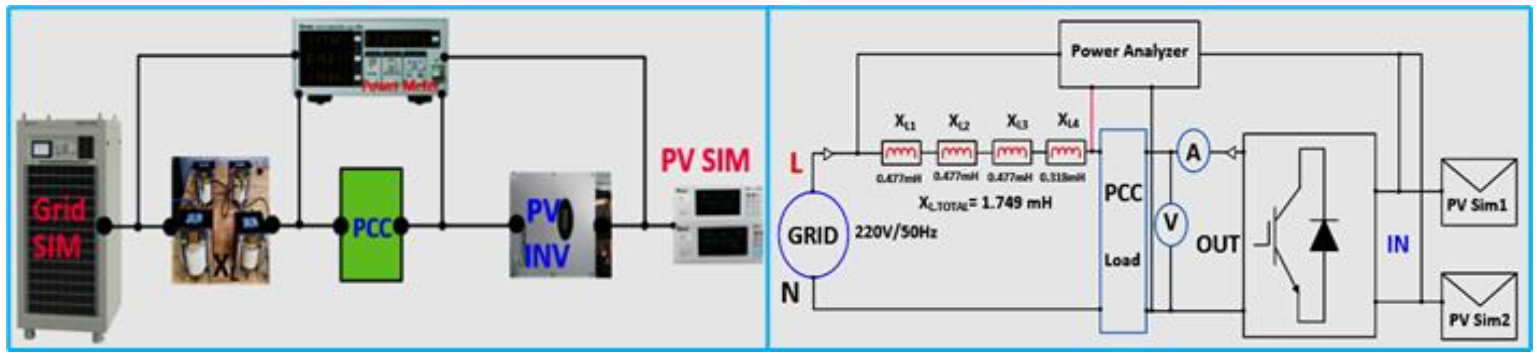

Figure 11. Experimental structure of a weak grid system connected XL

The results of a weak grid system passing impedance $\left(\mathrm{X}_{\mathrm{L}}\right)$ with $0.87 \Omega$ value penetrated power to a $\mathrm{PV}$ inverter show $\mathrm{P}_{\text {out }}$ in $100 \%$ power is $4995.1 \mathrm{~W}$ and there are power dips around $5 \mathrm{~W}$ in the system of $5 \mathrm{KW}$ inverter capacity. Naturally, power transmissions shall exist of power losses in the system and judiciously, a power transmission of a weak grid system passes an impedance $\left(\mathrm{X}_{\mathrm{L}}\right)$ and $\mathrm{X}_{\mathrm{L}}$ values are as consumed loads, therefore, power losses/growth are known from many causes such as; inverter output power, load power and system power. $\mathrm{I}_{\mathrm{PCC}}$ values in $100 \%$ and $66 \%$ power collapse slightly of pure current values, and $\mathrm{I}_{\mathrm{PCC}}$ dip factors caused by the grid power which run across impedance loads, internal grid impedance, and power quality problem. The active power in $100 \%$ application slows down slightly in the system after passing a grid impedance. Thus, $\mathrm{S}$ power sags caused by impedance values (Z), system conductors, and current rates depending on an applied equation, $\mathrm{S}$ power $=\mathrm{V} * \mathrm{I}$. Reactive power (Q) ratios under the distorted grid system place at good levels.

The system frequency values considered as stable values and $\max \mathrm{V}_{\text {PCC }}$ surges are around $1.48 \mathrm{~V}$ of basic voltage, thus voltage variation $(\Delta \mathrm{V})$ is equivalent to $0.67 \%$ of the system. Accurately, $\mathrm{V}_{\text {PCC }}$ surges caused by impedance load connected in series in the system. If according to a low voltage variation $(-10 \%$ and $+6 \%$ ) in Cambodia, $\Delta \mathrm{V}$ value does not exceed the power regulation of grid code. THDi growths rise quite highly over average values in the system as shown in Table 12 of each power application, judiciously, 
THD values occur by non-linear loads of the inverter circuit, grid impedances, and internal conductors of the system. THD affects can draw distorted current flow pathways and ripple current waveforms. The average values of THD for a grid are smaller than $1 \%$ and if according to THD value in power regulation of grid code Cambodia is not larger than $5 \%$ for a normal grid system.

Table 12. The results of a weak grid system with passing $\mathrm{X}_{\mathrm{L}}$ components

\begin{tabular}{cccccccccc}
\hline \multirow{2}{*}{ Description } & $\begin{array}{c}\mathrm{P}_{\text {OUT }} \\
(\mathrm{W})\end{array}$ & $\begin{array}{c}\mathrm{V}_{\mathrm{PCC}} \\
(\mathrm{V})\end{array}$ & $\begin{array}{c}\mathrm{I}_{\mathrm{PCC}} \\
(\mathrm{A})\end{array}$ & $\mathrm{P}_{\mathrm{ACT}}(\mathrm{KVA})$ & $\mathrm{P}_{\text {REAC }}(\mathrm{Kvar})$ & $\begin{array}{c}\text { Frequency } \\
(\mathrm{Hz})\end{array}$ & $\begin{array}{c}\text { PF } \\
(\%)\end{array}$ & $\begin{array}{c}\mathrm{V}_{\text {GRID }} \\
(\mathrm{V})\end{array}$ \\
\hline $100 \%$ & 4995.1 & 221.77 & 22.53 & 4.9957 & 0.07 & 49.99 & 0.99 & 1.81 & 220.29 \\
$66 \%$ & 3310.5 & 221.32 & 14.96 & 3.3109 & 0.04 & 50 & 0.99 & 2.32 & 220.25 \\
$33 \%$ & 1659.9 & 220.95 & 7.52 & 1.6614 & 0.07 & 49.99 & 0.99 & 3.53 & 220.26 \\
\hline
\end{tabular}

Figure 12 (a), Figure 12 (b) and Figure 12 (c) shows the waveforms of PCC voltage and PCC current during the grid simulator connected $\mathrm{X}_{\mathrm{L}}$ component in series and interfaced to PV simulator with $100 \%, 66 \%$ and 33\% power adjustment for the systematic process as shown in Figure 12 (a), Figure 12 (b) and Figure 12 (c) and the analysis results as demonstrated in Table 12.

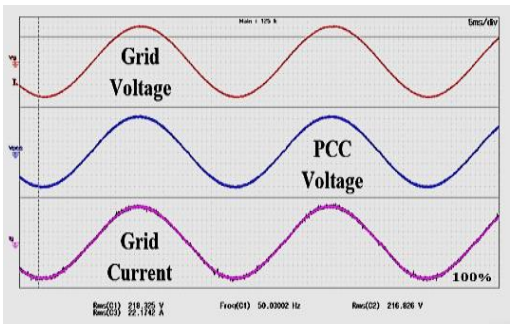

(a)

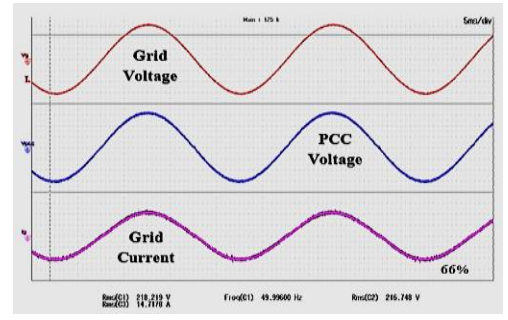

(b)

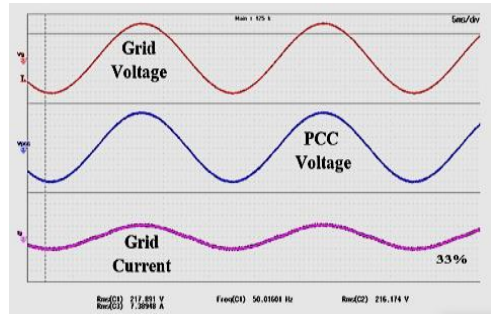

(c)

Figure 12. Waveforms of voltages and current (a) $100 \%$, (b) $66 \%$, (c) $33 \%$

Figure 13 specifies the evaluation between a systematic power and voltage feature of a weak grid system across $\mathrm{X}_{\mathrm{L}}$ as depicted in 3.3.1 while the system is applying with each power adjustment to discover the power system problem and voltage variations $(\Delta \mathrm{V})$.

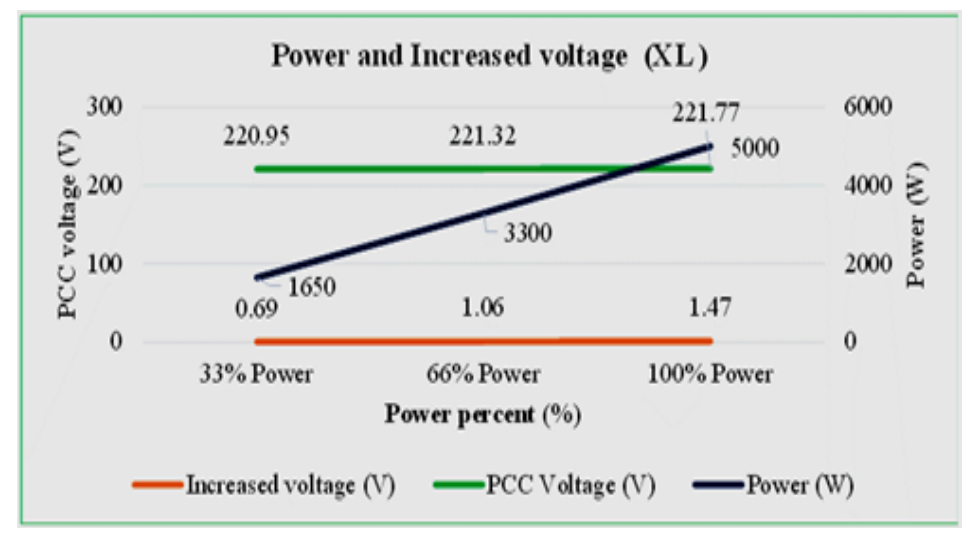

Figure 13. Comparison of power and voltage expansion

\subsubsection{Results of weak grid system connected inductive reactance $\left(X_{L}\right)$ and resistive units $(R)$}

The results of a weak grid system passing impedance $\left(X_{L}-R\right)$ with $2.619 \Omega$ value injected power with a PV inverter power exhibit $\mathrm{P}_{\text {out }}$ in $100 \%$ power collapses slightly about $2 \mathrm{~W}$ of $5 \mathrm{KW}$ inverter capacity, $\mathrm{P}_{\text {out }}$ in $66 \%$ power application rises around $19 \mathrm{~W}$ and $\mathrm{P}_{\text {out }}$ in $33 \%$ power application surges about $8 \mathrm{~W}$ of the grid system. Logically, power conveying factors could simply comprise power losses or growths in the systems. Judiciously, the power transmission of a weak grid system passes impedance $\left(X_{L}-R\right)$ values and $X_{L}-R$ values 
in series connection considered as consumed loads. Therefore, power loss/growth problems are known from many causes such as; an inverter output power, consumed load power, and a system power quality.

During the grid power of a weak grid system flows across impedance units $\left(\mathrm{X}_{\mathrm{L}}-\mathrm{R}\right)$ penetrated power with a PV inverter power, the $\mathrm{V}_{\mathrm{PCC}}$ ratio in $100 \%$ power rises to $238.11 \mathrm{~V}, 66 \%$ power grows up to $232.67 \mathrm{~V}$ and $33 \%$ power application spreads up to $226.64 \mathrm{~V}$. Particularly, $\mathrm{V}_{\mathrm{PCC}}$ expansion qualities are in $100 \%$ power is $18 \mathrm{~V}$ of a grid voltage and a voltage fluctuation $(\Delta \mathrm{V})$ gets equivalent to $8.18 \%, \mathrm{~V}_{\mathrm{PCC}}$ surge in $66 \%$ is given $12.34 \mathrm{~V}, \Delta \mathrm{V}$ value is equal to $5.60 \%$ and $\mathrm{V}_{\mathrm{PCC}}$ enlargement in $33 \%$ power gets $6.4 \mathrm{~V}$, therefore, $\Delta \mathrm{V}$ ratio is equal to $3 \%$ of an operating system. $\mathrm{V}_{\mathrm{PCC}}$ surges caused by a power quality problem and high grid impedance value. According to a low voltage fluctuation in Cambodia is between $-10 \%$ and $+6 \%$ of a normal operating system. Thus, $\Delta \mathrm{V}$ value in $100 \%$ power rises in $8.23 \%$ ratio which value exceeds power regulation and considered as overvoltage and the grid system shall be tripped by protective devices. S power in $100 \%$ application collapses slightly in the system after passing a grid impedance. Thus, $S$ power dip causes by impedance values (Z), system conductors, and current rates. System frequencies (f) considered in good stability range and reactive power (Q) stand in an enhanced situation of the system.

$\mathrm{I}_{\mathrm{PCC}}$ values as shown in Table 13 and the $\mathrm{I}_{\mathrm{PCC}}$ value in $100 \%$ power falls slightly around $2 \mathrm{~A}, 0.74 \mathrm{~A}$ for $66 \%$ power, and $0.18 \mathrm{~A}$ for $33 \%$ power application of pure current ratios. The $\mathrm{I}_{\mathrm{PCC}}$ declining factor causes a high grid impedance value $\left(\mathrm{X}_{\mathrm{L}^{-}} \mathrm{R}\right)$ of the system and power quality problems. Current THD values rise in quite a high level of the systems which exceed the average values $(<1 \%)$. The value $1.78 \%$ is for $100 \%$ power, $66 \%$ power comprises of $2.32 \%$ and $33 \%$ power consists of $3.60 \%$. The current distortions take place from non-linear loads of the inverter, grid impedance values, and power quality problems of the system. Although, current THD ratios do not yet exceed power regulation $(<5 \%)$ of grid code, Cambodia, the harmonic effects can absorb the distorted grid performance and ripple current waveforms.

Table 13. The results of a weak grid system with passing XL and R components

\begin{tabular}{cccccccccc}
\hline Description & $\begin{array}{c}\mathrm{P}_{\text {OUT }} \\
(\mathrm{W})\end{array}$ & $\begin{array}{c}\mathrm{V}_{\mathrm{PCC}} \\
(\mathrm{V})\end{array}$ & $\begin{array}{c}\mathrm{I}_{\mathrm{PCC}} \\
(\mathrm{A})\end{array}$ & $\mathrm{P}_{\mathrm{ACT}}(\mathrm{KVA})$ & $\mathrm{P}_{\text {REAC }}(\mathrm{Kvar})$ & $\begin{array}{c}\text { Frequency } \\
(\mathrm{Hz})\end{array}$ & PF & $\begin{array}{c}\text { THDi } \\
(\%)\end{array}$ & $\begin{array}{c}\mathrm{V}_{\text {GRID }} \\
(\mathrm{V})\end{array}$ \\
\hline $100 \%$ & 4998.6 & 238.11 & 20.99 & 4.9987 & 0.02 & 49.99 & 0.99 & 1.78 & 220.32 \\
$66 \%$ & 3319.2 & 232.67 & 14.27 & 3.3206 & 0.09 & 50 & 0.99 & 2.32 & 220.33 \\
$33 \%$ & 1658 & 226.64 & 7.32 & 1.6592 & 0.06 & 49.99 & 0.99 & 3.60 & 220.24 \\
\hline
\end{tabular}

Figure 14 exhibits a discussion between the systematic power and voltage features of a weak grid system across $X_{L}$ and $R$ in total values $2.619 \Omega$ as modified in 3.3.2. In addition, this system is emphasized on the findings of the power system troubles and voltage variations $(\Delta \mathrm{V})$.

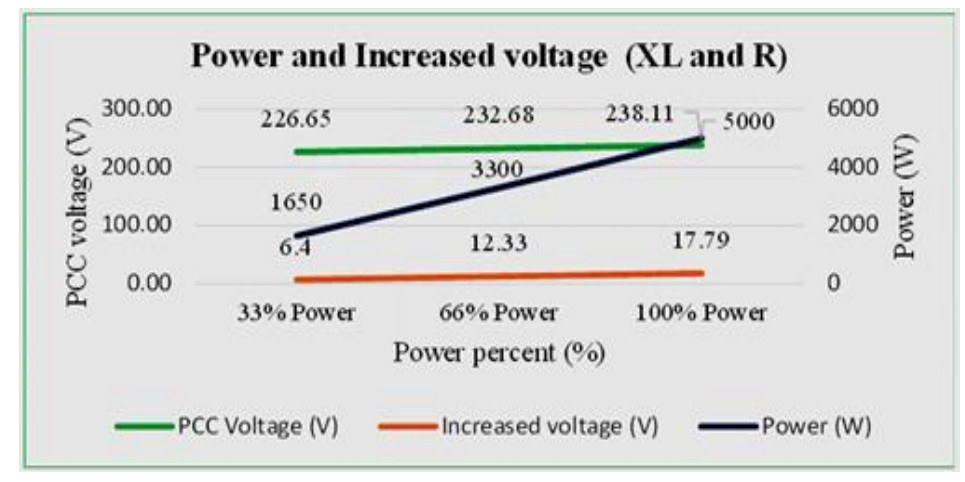

Figure 14. Output power and increased voltage of weak grid-connected $\mathrm{X}_{\mathrm{L}}$ and $\mathrm{R}$

Figure 15 (a), Figure 15 (b) and Figure 15 (c) exhibit the waveform features under a weak grid system which operating across XL and R values that they connected in series with a grid simulator by emphasizing on power system (PSYS), VG, IPCC and VPCC as depicted in 3.3.2 of a weak grid system (XL and $\mathrm{R})$. 


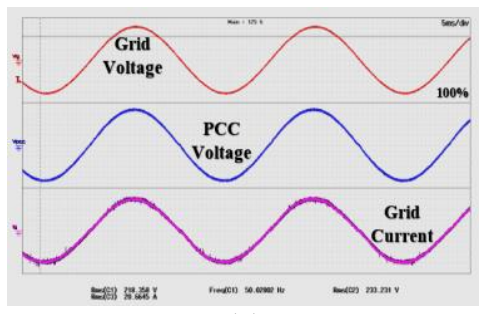

(a)

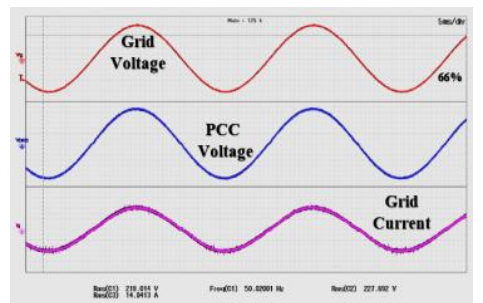

(b)

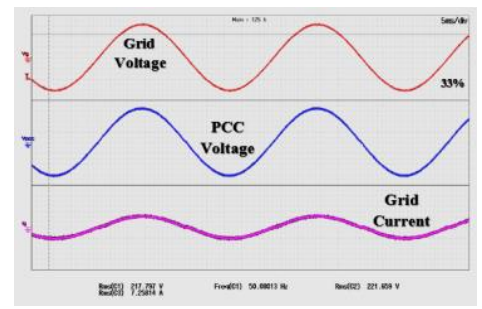

(c)

Figure 15. Voltage and current waveforms of the weak grid system connected $\mathrm{X}_{\mathrm{L}}$ and $\mathrm{R}$ (a) $100 \%$, (b) $66 \%$, (c) $33 \%$

\section{CONCLUSION}

In this paper, a single-phase grid-connected PV inverter performance under a weak grid verified the impacts on the grid systems. Simulations were done by using oscilloscope and power meter system block sets. System impacts were power quality problems, high $\Delta \mathrm{V}$ surges and THD rises which were capable of distorting seriously grid systems and draw extremely ripple current waveforms in the grid. The results exhibited judiciously in 33\% power applications under the percent rate additions on harmonic orders and the only $3^{\text {rd }}$ harmonic order selections, current THD quantities increase highly to exceed power regulation of grid code of Cambodia. These factors were caused by percent additions on harmonic including internal grid impedance. $\mathrm{V}_{\mathrm{PCC}}$ in $100 \%$ power application of a weak grid system $\left(\mathrm{X}_{\mathrm{L}}-\mathrm{R}\right)$ rises to $238.11 \mathrm{~V}$. Hence $\Delta \mathrm{V}$ was equivalent to $8.18 \%$ in the grid system which was caused by consumed charges and high grid impedance and this $\Delta \mathrm{V}$ exceeded a power regulation of Cambodia. Furthermore, the system could be disconnected by the protective devices while $\mathrm{I}_{\mathrm{PCC}}$ collapses about $2 \mathrm{~A}$ of $23 \mathrm{~A}$ pure grid value. Due to the decreasing factors in $\mathrm{I}_{\mathrm{PCC}}$ that came from voltage expansion rate and $\mathrm{X}_{\mathrm{L}}$ and $\mathrm{R}$-value factors in the grid. The entire experimental results observed the active and reactive power performances in good operating process without impacts on the grid system.

\section{ACKNOWLEDGEMENTS}

I would like to express my profound gratitude to the scholarship program of Her Royal Highness Princess Maha Chakri Sirindhorn of Thailand, through which I was provided a valuable opportunity to pursue my graduate study. I would also like to thank Mr. Ros Peth, the president of Cambodian-Thai Skills Development Institute, who provided me with financial support throughout the production process of this research paper.

\section{REFERENCES}

[1] VDB-Loi, "Cambodia-Power-Update," Phnom Penh: VDB Loi, 2018.

[2] SUNTRACE, "Solar Market Brief Cambodia,” Berlin: Suntrace, 2018.

[3] V. Birunda Mary, I. W. Christopher, G. Themozhi, "3-Switch Single-Phase Inverter for PV System," International Conference on Power Engineering, Computing, and CONtrol, PECCON, 2017. pp. 674-681.

[4] S. K. Rajput, "Solar Energy-Fundamental Economic Energy Analysis," Northern India Textile Research Association; Apr. 2017.

[5] J. S. Jana, Hiranmay Das Bhattacharya, Konika, "A review of inverter topologies for single-phase grid-connected photovoltaic systems," Renewable and Sustainable Energy Reviews,vol. 72, pp. 1256-1270, May 2017, DOI: 10.1016/j.rser.2016.10.049.

[6] N. Kumar, B.K. Panigrahi, C. Chakraborty, H. M. Suryawanshi, V. Verma, "Integration of solar PV with lowvoltage weak grid system: Using normalized Laplacian kernel adaptive Kalman filter and learning based InC algorithm," IEEE Transactions on Power Electronics, vol. 34, no. 11, pp. 10746-10758, Nov. 2019, DOI: 10.1109/TPEL.2019.2898319.

[7] J. Hu, J. Zhu, J. M. Guerrero, "Voltage stabilization: A critical step toward high photovoltaic penetration. IEEE Industrial Electronics Magazine, vol. 13,no. 2, pp. 17-30, Jun. 2019, DOI: 10.1109/MIE.2019.2906844.

[8] A. D. Prasad, M. Rupesh, K. Neelashetty, "Solar Photovoltaic (PV) grid integration issues," International Journal for Modern Trends in Science and Technology (IJMTST), vol. 2, no.7, pp. 91-96, Jul. 2016.

[9] D. Zhang, Ruichi An, Thomas, "Effect of voltage unbalance and distortion on the loss characteristics of three-phase cage induction motor," IET Electric Power Applications, vol.12, no. 2,pp.264-70, Oct. 2018, DOI: 10.1049/ietepa.2017.0464.

[10] J. Khazaei, Peter Asrari, Arash Shafaye, A. B. Piyasinghe, Lakshan, "Review of HVDC control in weak AC grids," Electric Power Systems Research, vol. 162, pp. 194-206, Sep. 2018, DOI: 10.1016/j.epsr.2018.05.022. 
[11] M. G. Dozein, T. K. Saha, R. Yan R, "System strength and weak grids: fundamentals, challenges, and mitigation strategies. Australasian Universities Power Engineering Conference (AUPEC), 2018, pp. 1-7, DOI: 10.1109/AUPEC.2018.8757997.

[12] N. Vázquez, J. Vaquero, "Power electronics handbook method for single-phase grid-tied inverter," IEEE Transactions on Power Electronics, vol. 31, no.3, pp. 2139-2140.Mar. 2016.

[13] Everton Luiz de Aguiar, R. Cardoso, C. M. Stein, "Distributed Renewable Power Sources in Weak Grids-Analysis and Control," Renewable Energy-Utilisation and System Integration, pp. 199-225, May 2016, DOI: $10.5772 / 61613$.

[14] A. Adib, B. Mirafzal, X. Wang, F. Blaabjerg, "On stability of voltage source inverters in weak grids," Ieee Access, Jan. 2018, DOI: 10.1109/ACCESS.2017.2788818.

[15] S. S. Pande, R. Shaha, "Analysis of UPQC for Voltage Sag Compensation in Wind Farms to Weak Grid Connections," International Journal of Engineering and Techniques, vol. 4, no. 3, pp. 241-246, Jun. 2018

[16] Nawir M, "Integration of wind farms into weak AC grid," Doctoral dissertation: Cardiff Unviersity, 2017.

[17] S. Tuo, D. Jiandong, X. Ma, "Active and reactive power coordination control strategy of overvoltage for distributed PV integrated grid," The Journal of Engineering, vol. 2019,no. 16, Oct. 2018, DOI: 10.1049/joe.2018.8913.

[18] T. Hailu, L. Mackay, M. Gajic, J. A. Ferreira, "From voltage stiff to voltage weak dc distribution grid: Opportunities and challenges," IEEE 2nd Annual Southern Power Electronics Conference (SPEC), 2016, pp. 1-6.

[19] K. Mozdzynski, M. Malinowski, S. Stynski, "Simple grid current control under strongly distorted grid voltage," IECON 2017-43rd Annual Conference of the IEEE Industrial Electronics Society, 2017. pp. 5380-5385.

[20] Patsalides ME. The effect of Solar irradiance on the power quality behaviour of grid connected photovoltaic systems, RE and PQJ, 2014, DOI: 10.24084/repqj05.284.

[21] EAC, "Electric power technical standard of the Kingdom of Cambodia," Phnom Penh: Electricity Authority of Cambodia (EAC), 2004.

[22] V. Vai, "Planning of low voltage distribution system with integration of PV sources and storage means: case of power system of Cambodia," Doctoral dissertation: Université Grenoble Alpes, 2017.

[23] EA, "On general conditions for connecting solar generation sources to the electricity supply system of national grid or to electrical system of a consumer connected to the electricity supply system of national grid," Phnom Penh: Electricity Authority of Cambodia EAC, 2018.

[24] Vai V, "Planning of low voltage distribution system with integration of PV sources and storage means: case of power system of Cambodia," [Doctoral dissertation]: Université Grenoble Alpes, 2017.

[25] EAC, "On general conditions for connecting solar generation sources to the electricity supply system of national grid or to electrical system of a consumer connected to the electricity supply system of national grid," Phnom Penh: Electricity Authority of Cambodia (EAC), 2018. 